\title{
Effect of oven and forced convection continuous tumble (FCCT) roasting on the microstructure and dry milling properties of white maize
}

\author{
Letitia Schoeman ${ }^{\mathrm{a}}$, Anton du Plessis ${ }^{\mathrm{b}}$, Pieter Verboven ${ }^{\mathrm{c}}$, Bart M. Nicolai ${ }^{\mathrm{c}}$, Dennis Cantre ${ }^{\mathrm{c}}$, Marena Manley ${ }^{\mathrm{a}, *}$ \\ a Department of Food Science, Stellenbosch University, Private Bag X1, Matieland, Stellenbosch 7602, South Africa \\ ${ }^{\mathrm{b}}$ CT Scanner, Central Analytical Facility, Stellenbosch University, Private Bag X1, Matieland, Stellenbosch 7602, South Africa \\ ${ }^{c}$ KU Leuven, Department of Biosystems, MeBioS, De Croylaan 42, 3001 Leuven, Belgium
}

\section{A R T I C L E I N F O}

\section{Keywords:}

Maize kernels

$\mathrm{X}$-ray micro-computed tomography

Image analysis

Milling yield

Kernel hardness

Material density

\begin{abstract}
A B S T R A C T
The effect of oven and forced convection continuous tumble (FCCT) roasting on the microstructure of whole maize kernels was characterised and quantified using X-ray micro-computed tomography $(\mu \mathrm{CT})$. The three-dimensional (3-D) volumes, reconstructed from the two-dimensional (2-D) images, were segmented into regions of interests (ROIs), i.e. air, germ, floury and vitreous endosperm, and each region quantified. Oven roasting was associated with a larger increase in total kernel volume (10.8\%) than FCCT roasting (3.4\%) as well as a significant $(\mathrm{P} \leq 0.05)$ decrease in whole kernel relative density (oven $=6.3 \%$; FCCT $=1.9 \%$ ). FCCT roasting had almost no effect on material density, in contrast to a significant $(\mathrm{P} \leq 0.05)$ decrease of $5.0 \%$ during oven roasting. Subsequent validation of the dry milling properties, i.e. percentage hominy chop, milling yield and hectolitre mass (HLM), indicated no significantly $(\mathrm{P}>0.05)$ detrimental effect by either of the roasting methods.

Industrial relevance: Roasting of maize can improve sensory, shelf life, nutritional and antioxidant properties with subsequent use in ready-to-eat foods and breakfast cereals. Roasting will inevitably affect the structure of maize, which in turn will affect the quality of the end product. This prompted the demand for non-destructive techniques that directly measure microstructural properties of food in order to link structure with quality. X-ray $\mu \mathrm{CT}$ in combination with image analysis uniquely illustrated the microstructural changes occurring during conventional oven and innovative FCCT roasting respectively. Furthermore, dry milling properties are important indicators of quality characteristics for the dry milling industry. The method described in this article can be applied to any food material to investigate structural properties.
\end{abstract}

\section{Introduction}

Maize (Zea mays L.) is one of the largest and most important crops produced worldwide contributing to an annual yield of over 1 billion ton in 2013 (Food and Agriculture Organization of the United Nations [FAOSTAT], 2015). A maize kernel consists of four main parts, i.e. endosperm (80-85\%), germ (10-14\%), pericarp (5-6\%) and an aleurone layer (2-3\%) (Delcour \& Hoseney, 2010). Typical processed foods produced from maize include breads, breakfast cereals, tortillas, corn chips and snack bars. Depending on the locality and ethnic group, maize can also be prepared and consumed in a variety of other ways, i.e. sundried, fermented, cooked, pounded or roasted (Oboh, Ademiluyi, \& Akindahunsi, 2010). Lately there has been an increasing demand for crunchy snack products, and competition for improved products is de- veloping in the industrial sector (Mrad, Debs, Saliba, Maroun, \& Louka, 2014). Traditionally, roasting is a dry thermal treatment, and it is still being used today for the preparation of healthy, crunchy maize snacks (Mrad et al., 2014). Flour obtained from roasted ground maize is also consumed by diverse ethnic groups in Northern Mexico and the Southern United States (Carrera, Utrilla-Coello, Bello-Pérez, Alvarez-Ramirez, \& Vernon-Carter, 2015). Roasted cereal grains, with improved organoleptic, shelf-life, nutritional as well as antioxidant properties, can easily be incorporated into ready-to-eat foods and breakfast cereals (Chung, Chung, \& Youn, 2011; Gujral, Sharma, \& Sharma, 2013; Murthy, Ravi, Bhat, \& Raghavarao, 2008; Oboh et al., 2010). On the other hand, severe roasting conditions could cause damage to chemical components (i.e. polyphenols and anthocyanin) thereby decreasing their antioxidative activity (Mrad et al., 2014).

\footnotetext{
* Corresponding author.

Email address: mman@sun.ac.za (M. Manley)
} 
In Southern Africa, dry milling is used to produce products such as samp (cooked, coarsely broken maize kernels of which the pericarp has been removed), maize grits and meal for human consumption. Roasting could potentially serve as a pre-processing step to enable the use of less energy for milling, to produce value-added products, or to extend the shelf life of products. Roasting of sorghum grains increases the water-absorbing capacity for the preparation of instant mixes and porridges (Ranganathan, Nunjundiah, \& Bhattacharya, 2014). In a recent study, pinole, a traditional energy food obtained from toasted ground maize, was shown to result in a significant increase in total available starches and in vitro hydrolysis rate (Carrera et al., 2015), making it a suitable ingredient for specialised energy cereal bar products.

Roasting influences cereal grains by making kernels softer due to the loss of endosperm structure and increased porosity (Murthy et al., 2008), which could be beneficial depending on the processing method and desired final product. There has been increasing interest in the use of roasted grains in food products due to potential health benefits, such as improved digestibility (Krings \& Berger, 2001) and bioavailability of minerals because of the greater loss of phytic acid during roasting (Khan, Zaman, \& Elahi, 1991). Roasting is considered one of the most effective methods of reducing aflatoxin levels (Kabak, 2009). It does, however, affect the quality and structure of grains, as their functional, technological, physiochemical and nutritional properties are strongly affected by structure-property relationships (Frisullo, Barnabà, Navarini, \& Del Nobile, 2012). This has spurred the need for non-destructive techniques to characterise and quantify microstructural changes.

Microscopic techniques such as scanning electron microscopy (SEM) and transmission electron microscopy (TEM) are commonly used to examine the internal structure of products (Suresh \& Neethirajan, 2015). These methods are, however, invasive and destructive, as they require sample preparation, which may in addition lead to the formation of artefacts. From an engineering perspective, three-dimensional (3-D) microstructural information of foods is more suited to a better understanding of food properties to determine processing parameters correctly. X-ray micro-computed tomography $(\mu \mathrm{CT})$ is a non-destructive and non-invasive imaging technique that can be used for high-resolution 3-D visualisation and characterisation of the internal morphology of a wheat sample (Suresh \& Neethirajan, 2015). X-ray $\mu$ CT is less costly and more convenient than MRI (Herremans et al., 2014; Lammertyn et al., 2003). Although neither of these methods requires sample preparation or chemical fixation, X-ray $\mu \mathrm{CT}$, in addition, enables analysing and visualising the structural design of cellular materials down to a few micrometres (Maire \& Withers, 2014) and now also into the submicron range (nano-tomography) (Withers, 2007). Furthermore, X-ray $\mu \mathrm{CT}$ measures density, whereas MRI provides information on the water content and mobility (Herremans et al., 2014).

Lately, X-ray $\mu \mathrm{CT}$ has been the subject of numerous research articles on non-invasive quantitative and qualitative analysis of the internal quality of agricultural products (Herremans et al., 2013). It has also been used to study the structure of porous cereal products (Van Dalen, Nootenboom, \& Van Vliet, 2007), rice (Witek et al., 2010; Zhu et al., 2012), foams (Lim \& Barigou, 2004), extruded products (Zhu et al., 2010), bread (Lassoued, Babin, Della Valle, Devaux, \& Réguerre, 2007), wheat flour dough (Bellido, Scanlon, Page, \& Hallgrimsson, 2006), fruit tissue (Cantre, East et al., 2014; Cantre, Herremans, Verboven, Ampofo-Asiama, \& Nicolaï, 2014; Herremans et al., 2015; Mendoza et al., 2007; Verboven et al., 2008), chocolate (Haedelt, Beckett, \& Niranjan, 2007) and processed meat (Frisullo, Marino, Laverse, Albenzio, \& Del Nobile, 2010). Individual maize kernel volume and density could be measured accurately using this technique (Guelpa, Du Plessis, Kidd, \& Manley, 2015; Gustin et al., 2013). The use of X-ray $\mu \mathrm{CT}$ for characterisation of food microstructure has recently been comprehensively reviewed (Schoeman, Williams, Du Plessis, \& Manley, 2016).

A recent study demonstrated the effectiveness of X-ray $\mu \mathrm{CT}$ to evaluate the effect of forced convection continuous tumble (FCCT) and oven roasting on the microstructure of wheat non-destructively (Schoeman, Du Plessis, \& Manley, 2016). Oven roasting resulted in more adverse microstructural changes (increased porosity and decreased relative density) observed in the endosperm, compared to whole wheat grains roasted at the same time and temperature combination. In contrast to wheat, maize endosperm comprises two types, i.e. vitreous and floury. Hard maize kernels with a larger proportion of the denser vitreous endosperm are favoured by the dry milling industry as it produces greater milling yield and higher-quality meals and grits than softer maize. Large intact grits, which are essentially the vitreous endosperm removed from the kernel, are required for cornflake production. In the case of maize, it is thus important to evaluate the effect of roasting on the two endosperm matrices individually.

Dry milling quality is determined by percentage hominy chop, milling yield and hectolitre mass (HLM). The percentage hominy chop is considered to be one of the most appropriate methods to determine milling quality (Guelpa, Bevilacqua et al., 2015). Good milling characteristics are indicated by a small percentage hominy chop. Hominy chop (containing pericarp, tip cap, germ and some endosperm) is of less value than maize meal and grits, and it is mainly used as animal feed. A large hominy chop (above $30 \%$ ) is delivered by maize that mills poorly (typically soft maize kernels) since floury endosperm breaks down easily and is also included in the chop. A good milling quality maize would have a hominy chop below $22 \%$ (Guelpa, Bevilacqua et al., 2015).

Milling yield or extraction is the percentage of meal obtained after dry milling, and is one of the most important factors for millers. A higher value indicates a higher extraction of high-grade and most profitable products, e.g. samp and grits (degermed products) that are manufactured from the vitreous part of the endosperm (The South African Grain Laboratory [SAGL], 2016). Kernel hardness affects the quality and quantity of the milled products. Roasted cereal grains may influence milling yield since they are generally characterised by decreased kernel hardness, due to the increased internal porosity of the endosperm (Raigar, Prabhakar, \& Srivastav, 2017). HLM gives a good indication of potential milling quality, as there is a positive correlation between HLM, milling yield and kernel hardness (Guelpa, Bevilacqua et al., 2015).

The aim of the present study was to quantify and visualise the effect of oven and FCCT roasting on the microstructure of whole maize kernels in terms of volume, porosity and relative density of such maize kernels, the vitreous and floury endosperm, and other selected regions of interests (ROIs). Analytical validation of the effect of roasting on dry milling properties was illustrated by means of HLM, hominy chop and milling yield.

\section{Materials and methods}

\subsection{Maize samples}

Twenty whole maize kernels were randomly selected from a white maize sample, kindly provided by PANNAR Seeds (Greytown, South Africa). To allow direct comparison, the same kernels were imaged with $\mathrm{X}$-ray $\mu \mathrm{CT}$ before (control) and after roasting. Ten kernels were subjected to oven roasting and ten to FCCT roasting. The kernels were weighed before and after roasting to determine the percentage weight loss, and were stored in airtight containers at ambient temperature. 


\subsection{Roasting}

Maize samples were roasted at $180{ }^{\circ} \mathrm{C}$ for $140 \mathrm{~s}$ using two roasting techniques: conventional convection oven roasting (831 Electric Multifunction Thermofan Solid Plate Oven, Defy Appliances, Durban, South Africa) and patented FCCT roasting (Roastech, Bloemfontein, South Africa). A temperature of $180{ }^{\circ} \mathrm{C}$ is commonly used for roasting cereal grains (Chung et al., 2011).

During FCCT roasting, the roasting time can be controlled by means of the rotating speed of the screw conveyer inside the roasting chamber. A speed setting of $80 \mathrm{~Hz}$ is equivalent to $140 \mathrm{~s}$. The individual kernels were numbered for direct comparison of the X-ray images before and after roasting for both methods. Each white maize kernel was roasted, mixed in a $200 \mathrm{~g}$ yellow maize sample. The ten kernels were roasted individually for each roasting method; thus, ten replicates per roasting treatment. High thermal efficiency was achieved during FCCT roasting since the steam was circulated and re-used during the roasting operation.

For the FCCT roaster, a 15-min start-up time was permitted to obtain steady-state conditions before roasting. The conventional convection oven was pre-heated to $180{ }^{\circ} \mathrm{C}$ before placing the numbered kernel together with $200 \mathrm{~g}$ of yellow maize on a stainless steel baking tray and into the oven. The fan of the convection oven circulated the heat throughout the interior of the oven and a portable thermometer was placed inside the oven to measure the air temperature. After roasting, the samples were immediately cooled to ambient temperature by spreading it on a cold surface to stop exothermic reactions and further moisture loss. The samples were stored in airtight containers (at ambient temperature) until X-ray $\mu \mathrm{CT}$ image acquisition.

\subsection{X-ray micro-computed tomography $(\mu \mathrm{CT})$ image acquisition}

All maize kernels were individually imaged under identical conditions. X-ray $\mu \mathrm{CT}$ scans of the raw and roasted whole maize kernels were obtained using a General Electric Phoenix V | Tome | X L240 (General Electric Sensing \& Inspection Technologies GmbH, Phoenix, Wunstorff, Germany) high-resolution X-ray computed tomography (CT) system. CT scans (tomograms) with a voxel size (resolution) of $12 \mu \mathrm{m}$ were obtained using the scanning parameters described by Schoeman et al. (2016a). These settings were used since it resulted in high-quality images while considering both resolution and scanning time. Images were captured using a 16-bit flat-panel X-ray detector ( $2048 \times 2048$ pixels). A series of 2-D radiographic X-ray images were acquired during rotation, with 500 milliseconds (ms) exposure time per image, recording 1500 images in one rotation. Detector shift was activated to minimise ring artefacts. Background calibration was performed, and the scan time was approximately $25 \mathrm{~min}$ per scan.

Fig. 1 details the experimental design for determining the effect of roasting on the microstructure of whole maize kernels. Each maize kernel was mounted vertically on a piece of oasis (floral foam) and a polytetrafluoroethylene (PTFE) polymer disc (10 mm thickness and $25 \mathrm{~mm}$ diameter), obtained from Maizey Plastics (Cape Town, South Africa), on the translation stage (see sample setup in Fig. 1). The polymeric disc (density of $2.15 \mathrm{~g} / \mathrm{cm}^{3}$ ) was used as reference standard for relative density determinations and was thus scanned in the field of view (FOV).

\subsection{Image processing and analysis}

Image processing and analyses were performed as described by Schoeman, Du Plessis et al. (2016). Reconstruction was done using sys- tem-supplied Datos reconstruction software (Datos $\mid x{ }^{\circledR}$ 2.1, General Electric Sensing \& Inspection Technologies GmbH, Phoenix, Wunstorff, Germany). This software reconstructs the 2-D X-ray projection images into a 3-D volume (Fig. 1), which consists of individual voxels (3-D pixels) of which each is mapped to a 16-bit grey-value.

Low-density materials attenuate X-rays less than high-density components, which correspond to low and high grey-values respectively. In this case, the grey-values depended on the densest object in the scan volume, which was the polymer disc. Gaussian filtering and beam-hardening correction steps were applied to suppress random noise and beam-hardening artefacts respectively. Image analysis was performed with Volume Graphics VGStudio Max 2.2 software (Volume Graphics, Heidelberg, Germany). Before quantification of microstructural parameters, the following image analysis steps were performed: creation of axial images (cross-sectional slices), segmentation of grey-level images, defining and extraction of ROIs, and lastly, 3-D analysis to calculate structural properties and morphological descriptors.

Additional high-resolution scans were performed on the interface section between the two endosperm matrices of three respective maize kernels - raw, FCCT- and oven-roasted - using a Phoenix Nanotom S system (General Electric Sensing and Inspection Technologies/Phoenix $\mathrm{X}$-ray, Wunstorff, Germany). An accelerating voltage of $60 \mathrm{kV}$ and current of $200 \mu \mathrm{A}$ were required to obtain a resolution of $2 \mu \mathrm{m}$. The resulting scan time was $1 \mathrm{~h}$. Skeletonisation was performed on these images using Avizo 9.0 software (VSG, Bordeaux, France). The skeletonisation algorithm was applied to a binary smoothed version of the segmented image to generate a 3-D spatial distribution, which indicates the topology, geometry and connectivity of the porous network in the extracted skeleton. The software computes the skeleton by generating points (nodes) at every porous region and then interconnects these nodes by lines, referred to as 'segments'. This algorithm finds, labels and tracks the medial axis of the porous network, and is therefore a simplified representation of the centre lines of the air paths. In the present study, the segments were colour-coded based on their thickness.

\subsubsection{Segmentation and defining ROIs}

The Simple registration tool was used to align cross-sectional slice images in VGStudio Max 2.2 software. A cleaning step, using an Adaptive gauss filter, was applied to remove pixels not of interest (noise). Grey-value-based segmentation, including removal of background, was performed using the Region growing and Adaptive rectangle tools. Once the background had been removed, ROIs (air, germ, vitreous and floury endosperm) were virtually segmented from the original reconstructed volumes using the Region growing tool. The germ and vitreous endosperm densities were very similar and prevented accurate segmentation of the endosperm; therefore, the germ was virtually removed (Fig. 1) using the Drawing tool.

\subsubsection{Quantitative measurements}

Quantitative measurements were performed using VGStudio Max 2.2 software. These included volume of interest (VOI; $\mathrm{mm}^{3}$ ), percentage object volume (POV; \%), porosity (\%), expansion ratio (ER), vitreous-to-floury endosperm ratio (V:F), and relative density $\left(\mathrm{g} / \mathrm{cm}^{3}\right)$ determinations. The unit for all volume measurements was $\mathrm{mm}^{3}$.

\section{i. Volumes of interest (VOIs)}

VOIs were measured using the Volume analyser tool, which automatically calculates the volume of the selected ROI. By creating different VOIs, volume measurements of specific kernel constituents (e.g. germ or floury endosperm) or the whole sample can be determined.

ii. Percentage object volume 


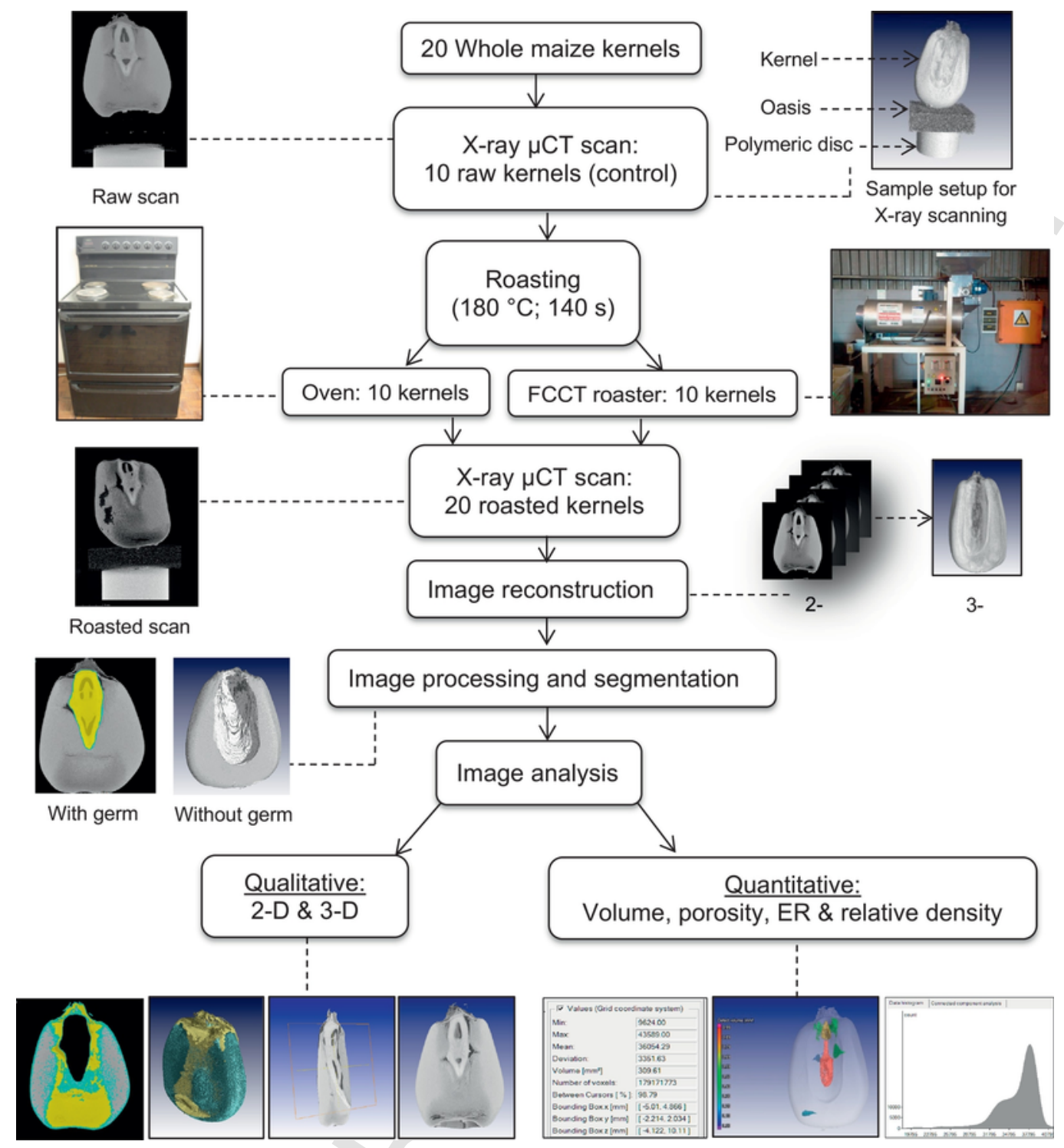

Fig. 1. Flow diagram of experimental design for determining the effect of oven and FCCT roasting on the microstructure of whole maize kernels using X-ray $\mu$ CT and image analysis.

$$
\mathrm{POV}=\frac{\text { VOI }}{\text { Total volume }} \times 100 \%
$$

iii. Porosity (total air volume fraction)

$$
\text { Porosity }=\frac{\text { Air volume }}{\text { Total volume }} \times 100 \%
$$

In the present study, 'porosity' referred to the total air volume, and was subdivided into large cavities and small pores. 'Cavities' referred to large air spaces (due to fusion of pores) and 'pores' were regarded as small intergranular air pockets with air pore volumes smaller than $0.100 \mathrm{~mm}^{3}$ and comprising $>8$ adjacent dark voxels $(12 \mu \mathrm{m})$, which are not always visible with the eye and are created by dehydration during drying. The Defect detection tool was used to perform a Custom defect mask to colour-code cavities according to size and to illustrate their arrangement. To determine the volume of pores, the Defect detec- tion tool (VGStudio Max 2.2) was applied after the exclusion of the cavities (Guelpa, Du Plessis et al., 2015). For each maize kernel, the volumes of cavities (percentage cavities) and pores (percentage pores) were calculated as a percentage of the total kernel volume.

iv. Expansion ratio (ER)

$\mathrm{ER}=\frac{\text { Volume after roasting }}{\text { Volume before roasting }}$

v. Vitreous-to-floury endosperm ratio (V:F)

$\mathrm{V}: \mathrm{F}=\frac{\text { Volume of vitreous endosperm }}{\text { Volume of floury endosperm }}$

vi. Relative density 


\section{Relative density

$$
=\frac{\text { Mean grey value of ROI }}{\text { Mean grey value of reference standard }} \times 2.15
$$

where 2.15 is the density $\left(\mathrm{g} / \mathrm{cm}^{3}\right)$ of the polymer disc.

\subsection{Dry milling properties}

A 25-kg commercial white maize variety provided by Sasko (Essential Foods, Division of Pioneer Foods (Pty) Ltd., Paarl, South Africa) was used to determine the effect of roasting on dry milling properties. The measurements were performed at the research and development facility of Sasko. The sample was cleaned using a Carter Day Dockage Tester and then mixed and divided into nine batches with a Boerner Divider (Seedburo Equipment Co., Chicago, USA). Three of the batches were treated as control samples and remained unroasted, while FCCT and oven roasting were performed in triplicate respectively, as described above, on the remaining six batches. Non-destructive HLM analysis was performed in duplicate, whereas milling yield and hominy chop were determined as single measurements due to the large sample sizes required for these destructive measurements.

The HLM (in $\mathrm{kg} \mathrm{hL}^{-1}$ ) of the samples was determined using a German Kern 220/222 Grain Sampler (KERN \& SOHN GmbH, Balingen-Frommern, Germany). This test was performed according to the method described earlier (Guelpa, Bevilacqua et al., 2015).

Maize was degermed using a pilot plant scale degermer and subjected to the milling process. Hominy chop (blend of pericarp, tip cap, germ and, to a lesser extent, floury endosperm) was calculated as a percentage of the total sample mass (Guelpa, Bevilacqua et al., 2015).

For milling yield determinations, degermed maize was subjected to dry milling using the Buhler MLU 202 Laboratory Mill (Buhler, Switzerland). The maize (900 g of each sample) was tempered to $15-16 \%$ moisture for $24 \mathrm{~h}$ before milling. Milling yield was assessed as the percentage of total weight accounted for by the combination of the following milling fractions: semolina, special and super.

\subsection{Statistical analysis}

One-way analysis of variance (ANOVA) was performed to compare averages for the respective quantitative measurements with respect to the two roasting methods. Data was reported as the mean $(\mathrm{n}=10) \pm$ standard deviation for X-ray $\mu \mathrm{CT}$ results and mean $(\mathrm{n}=3) \pm$ standard deviation for milling property analyses. Data analyses were performed using STATISTICA version 13 (StatSoft, Inc., Tulsa, USA). The level of confidence required for significance was selected at $\mathrm{P} \leq 0.05$.

\section{Results and discussion}

\subsection{Visual assessment}

All roasted maize kernels partially retained the light yellowish pigmentation due to the carotenoid content, despite the roasting method (Fig. 2), as was also observed by Carrera et al. (2015). Oven roasting, however, led to a much darker, yellow-brown, external colour compared to FCCT roasting. A previous study illustrated that, under similar conditions, superheated steam roasting is associated with less colour deterioration and increased drying and evaporation rates, resulting in smaller losses regarding nutritional value in comparison to hot air (Moreira, 2001). This could be attributed to less oxidation occurring during FCCT roasting using superheated steam (Schoeman, Du Plessis et al., 2016). Furthermore, oven-roasted samples had a bulged appear- ance, whereas FCCT-roasted samples were more uniform in shape. This indicates a more intense degree of roasting in the case of the oven method. The Maillard reaction occurs when reducing sugars are heated in the presence of free amino groups (e.g. amino acids, amines and proteins) (Odjo, Malumba, Dossou, Janas, \& Béra, 2012). This gives rise to the colour development during roasting. The floury and vitreous endosperm regions are situated near the centre and toward the outside of the kernels as opaque and translucent regions respectively (Fig. 2). In the present study, the raw kernel had no visible internal cracks, whereas internal cracks were observed in the floury endosperm of the FCCT-roasted and both endosperm regions of oven-roasted samples. The oven-roasted sample had a much darker internal colour.

\subsection{Qualitative image analysis}

Roasting is a time-temperature dependent process in which maize kernels undergo a series of reactions leading to several changes in their microstructure. Fig. 3 illustrates the central plane of the sagittal and horizontal views of the 2-D cross-sectional maize kernel images, acquired before and after roasting. As similar results were obtained, images of only one of the kernels are shown for each roasting method.

\subsubsection{Internal cracks, cavities, pores and porosity (2-D analysis)}

Differences in grey-level intensities (image contrast) correlate to density variations within the kernel. Black areas represent air voids, since they have a lower absorption coefficient with respect to kernel structure. In the raw kernels, the germ and vitreous endosperm are thus more dense components illustrated by a brighter region (Fig. 3). The softer floury endosperm is related to a less dense region portrayed by a darker grey scale.

Large internal cracks developed in the floury endosperm of both the oven-roasted and FCCT-roasted samples (Fig. 3). These cracks extended well into the vitreous endosperm; however, not reaching the pericarp, in the case of oven roasting. The pericarp remained intact and acted as a pressure vessel. When the internal water vapour pressure is greater than the material strength, internal cracks develop (Song \& Litchfield, 1994). It is also possible that crack development is initiated by differential expansion due to thermal or moisture gradients. The cracks seemed to initiate at the centre of the kernel since it narrowed when approaching the kernel surface. More voids were present in the floury compared to the vitreous endosperm, especially around the germ, for both roasted samples. Less structural interference in the vitreous endosperm region might be due to it being harder and having fewer intercellular spaces, making this region less susceptible to crack formation. An earlier study also observed stress cracks in maize during high-temperature processing (Shoughy, Marey, \& Abbas, 2009). Non-destructive light reflectance measurement and ultrasonic imaging were unsuitable to detect the presence of stress cracks, whereas 2-D X-ray imaging was used successfully (Gunasekaran \& Paulsen, 1986).

Fig. 4 illustrates the complexity and interconnectedness of the crack network by means of internal cavities (or cracks) and pores. The raw kernels had a dense internal structure with small cavities and only a few pores around the germ and in the floury endosperm (Fig. 4a). The roasted kernels had inconsistently distributed and partially interconnected cracks and large elongated cavities in the centre of the kernels, whereas smaller pores were particularly observed in the bottom region of the floury endosperm (Fig. 4b and c). The size of the cavities was much larger in the oven-roasted compared to the FCCT-roasted samples, resulting in an open porous structure. Roasting resulted in more cavities being formed in the floury compared to the vitreous endosperm. This was expected as the floury endosperm is known to have more intercellular spaces between the starch granules, than the vitreous endosperm, and thus more prone to form cracks. The oven-roasted kernels revealed much greater expansion and more air than the FCCT- 


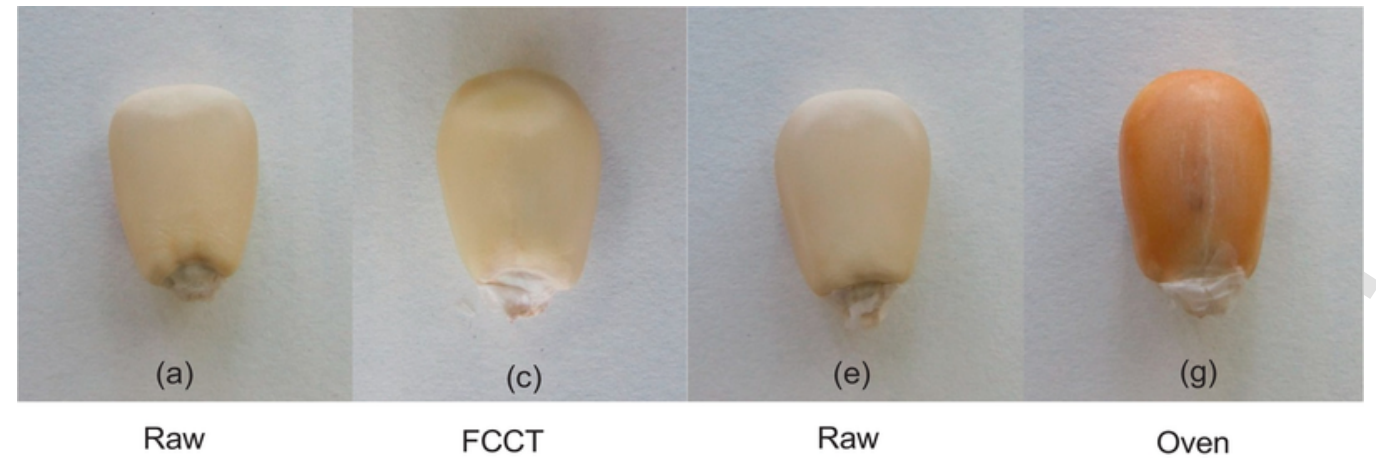

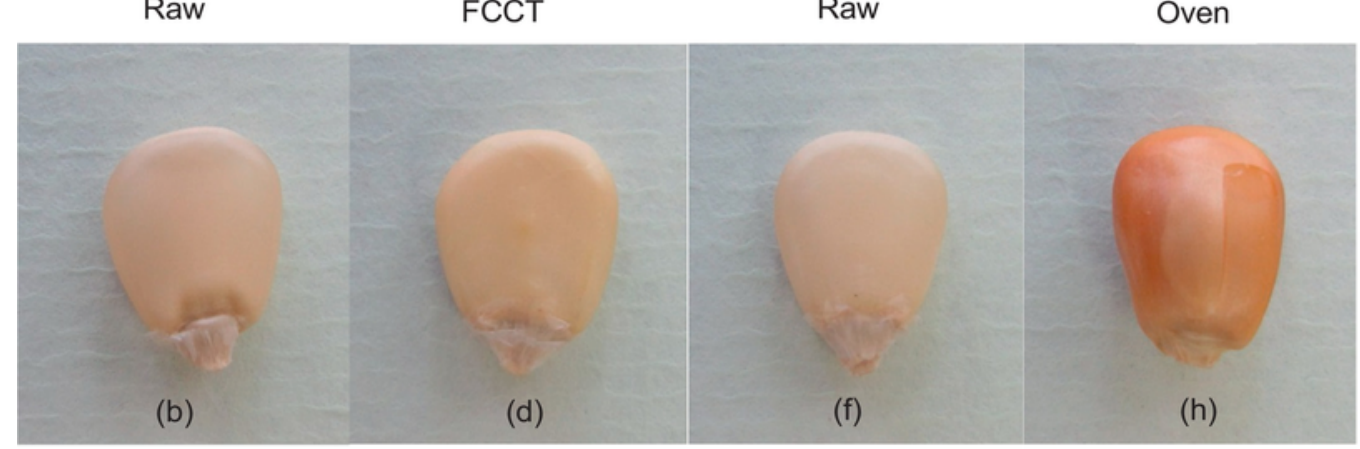

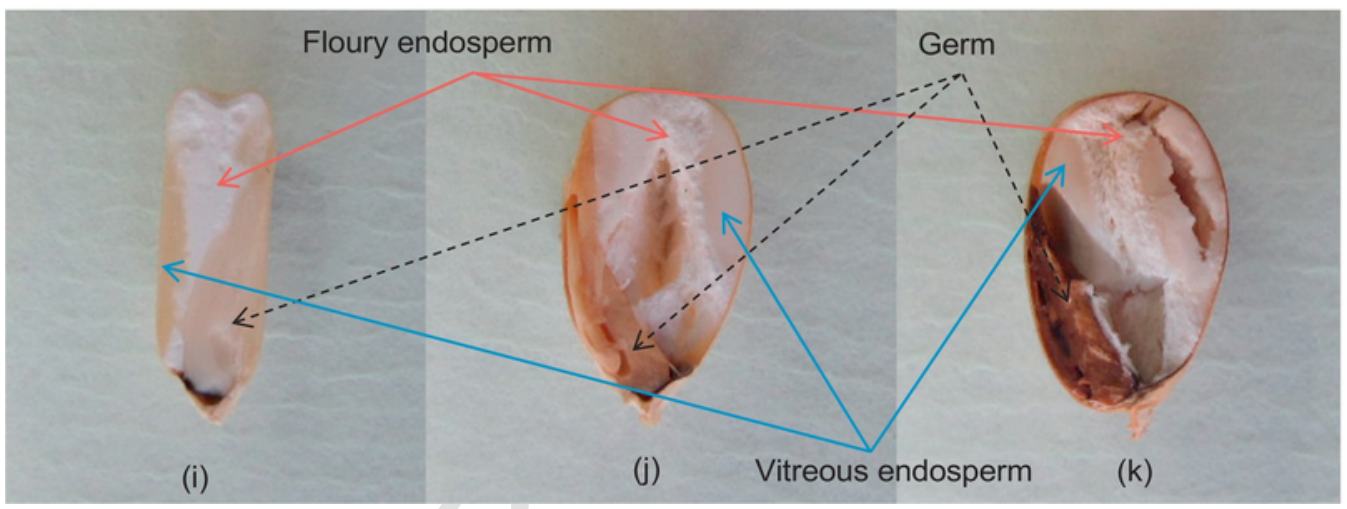

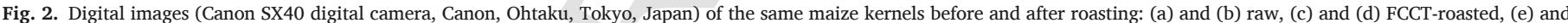

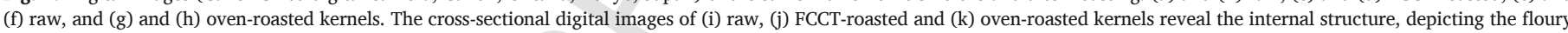
and vitreous endosperm regions as well as the germ (dashed arrow).

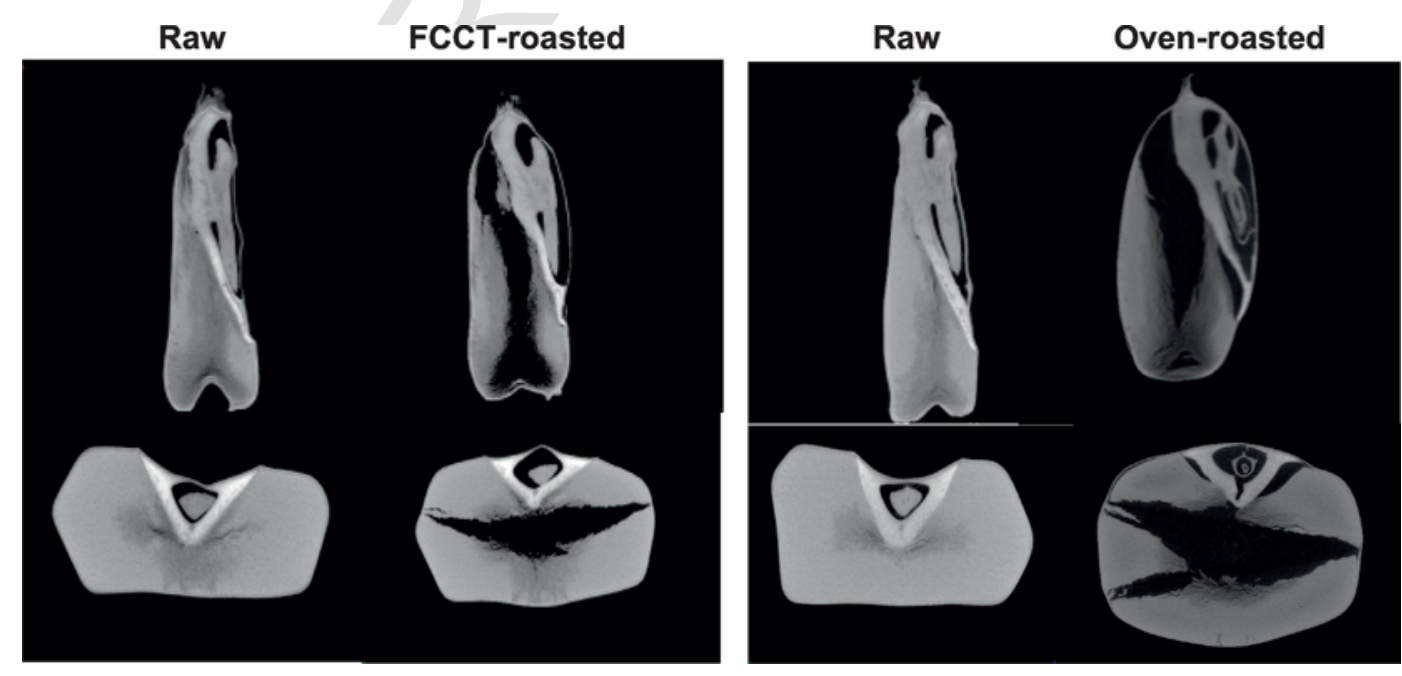

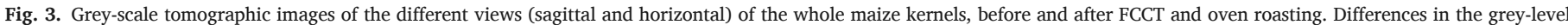
intensities indicate density variations (light grey $=$ high density; darker grey $=$ low density) while the black areas represent air voids. 

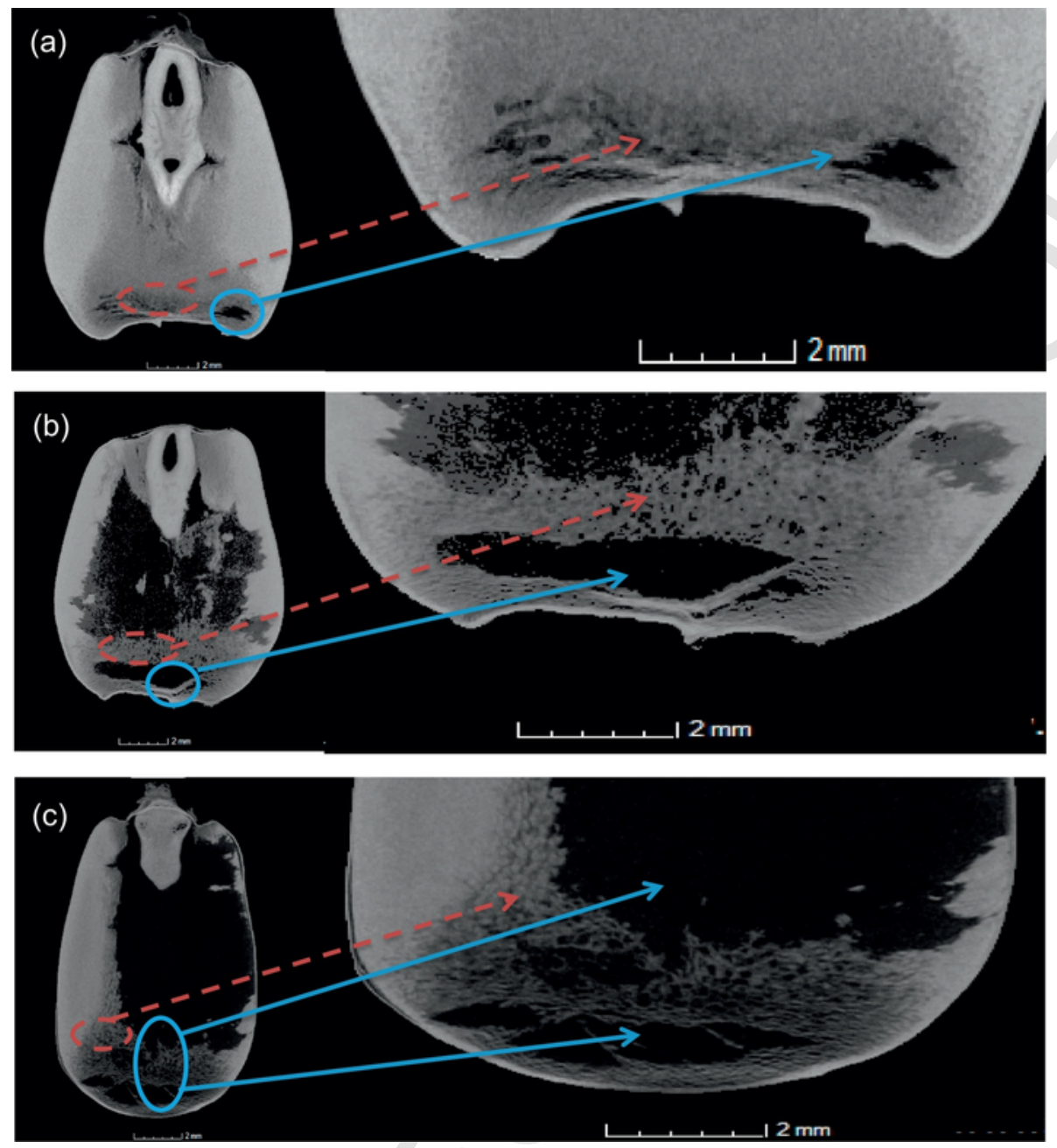

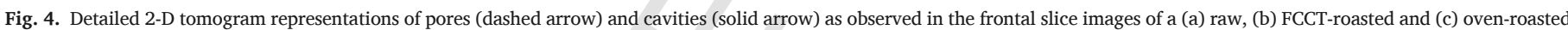
maize kernel.

roasted kernels resulting in a lower density (as discussed later in Section 3.3) in comparison to the FCCT-roasted samples (Fig. 3; sagittal view).

Cavities may have resulted from the fusion of a number of pores. During heat processing, coalescence of two or more pores takes place leading to the formation of large, asymmetric voids, resembling interconnected cavities (Pittia et al., 2011). Even though some researchers consider pore size a quality evaluator (Gonzales-Barron \& Butler, 2008), it has not been confirmed to date that pore characteristics could affect the final quality as perceived by the consumer. Air voids will, however, affect the density and hardness of the maize kernels, which in turn, will affect milling quality (Guelpa, Du Plessis et al., 2015).

The germ was generally intact, as the cracks did not propagate into this region (Fig. 3). Even though the outer layer of the germ, the scutellum, was in contact with the endosperm, it was still separate and discontinued from the endosperm (Wolf, Buzan, MacMasters, \& Rist, 1952). A thin hyaline band of non-cellular material occupies the space between the endosperm and the scutellum. It is possible that this structural discontinuity inhibits the propagation of cracks in the germ region. This will enable efficient degermination of roasted samples before milling. The germ is furthermore a more flexible tissue since it grows during germination.

Roasting causes the conversion of the moisture entrapped within a kernel into vapour and this results in the development of ruptures and a puffing effect or expansion in volume (Pardeshi \& Chattopadhyay,
2014). This vapour exerts pressure from within the kernel and leads to the development of cracks or fissures. It is through these cracks that the moisture ultimately escapes. Consequently, the cell walls separating pores get fractured and the pores increase in size, forming large cavities illustrated as irregular black voids (Figs. 3 and 4). These zones are probably created by a flash of superheated steam that partially damages the structure (Sumithra \& Bhattacharya, 2008).

\subsubsection{Porosity, cavities and pores (3-D analysis)}

Fig. 5 illustrates the porosity (subdivided into cavities and pores) before and after roasting in 3-D volume-rendered images and thus provides an indication of the cavity and pore size distribution. During roasting, the porosity increased. In the raw samples, separate cavities and pores were observed, whereas in the roasted samples, the cavities and pore networks were interconnected. Most of the cavities in the raw samples were located near the middle of the kernel, along the embryonic axis with pores in the floury endosperm. Pores as small as $41 \mu \mathrm{m}$ in diameter (FCCT-roasted; blue) could be detected, whereas the largest cavity was visible in the oven-roasted sample (dark red) (Fig. 5).

The oven-roasted sample had the highest porosity and a widely dispersed pore network, with the cavities contributing to the majority of the air present. Variations in the distribution of pores and cavities in the roasted kernels could be due to the effect of heat and mass (water vapour) transfer during volume expansion mechanisms that occur in the different regions (Pittia et al., 2011). It is implied that during roast- 


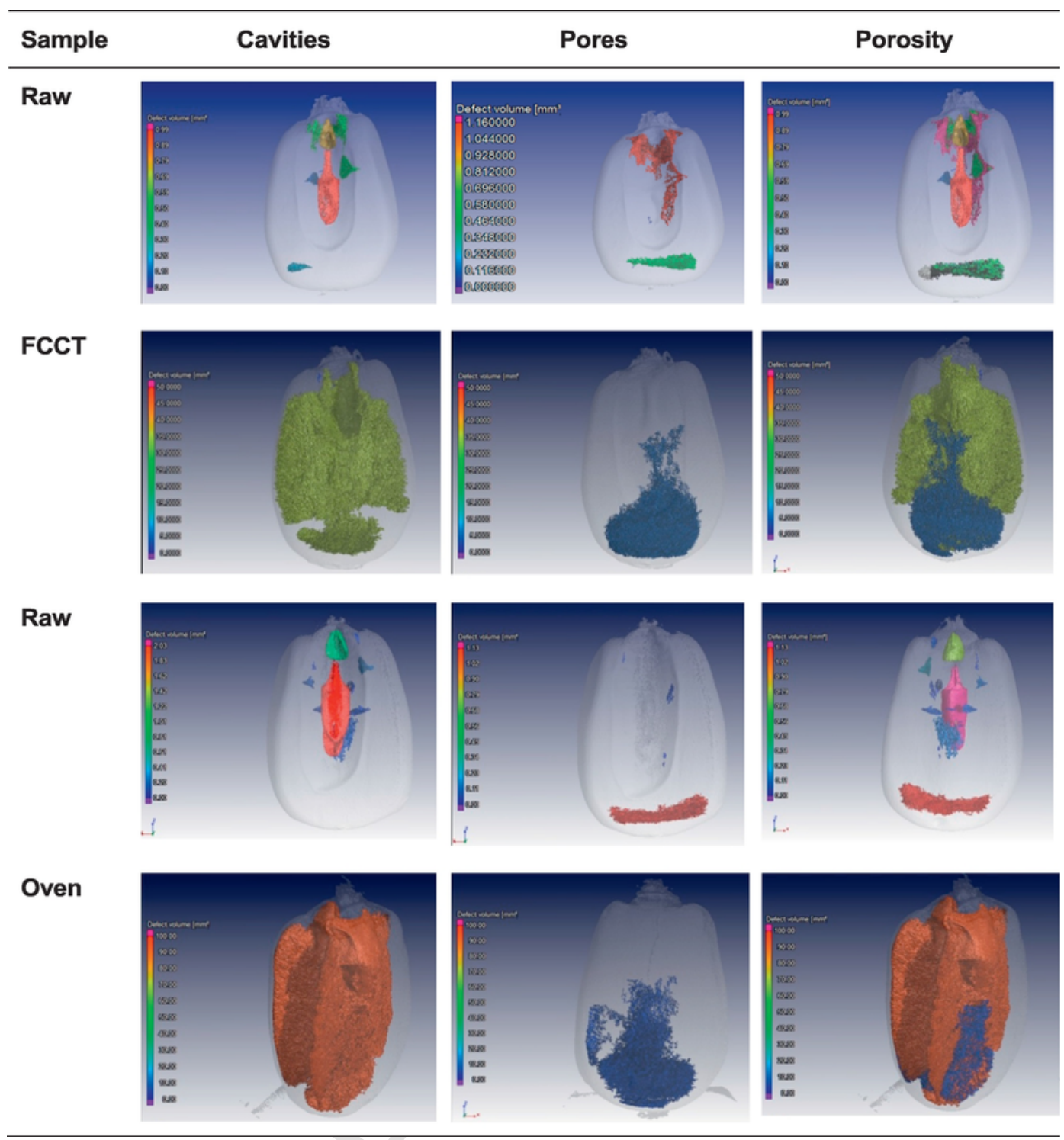

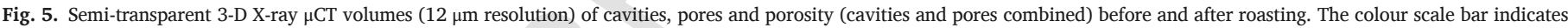

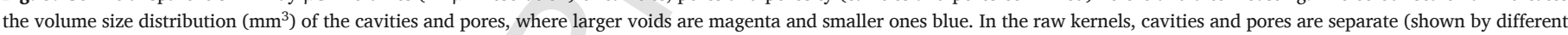

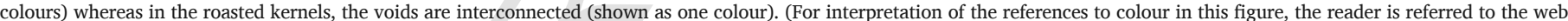
version of this article.)

ing, the increased internal pressure, as a result of the formation of water vapour, gave rise to the open porous structure. X-ray $\mu \mathrm{CT}$ analysis offers a precise estimate of the porosity and the effect of roasting on the internal microstructure.

Fig. 6 illustrates the three skeletonised models of raw, FCCT- and oven-roasted maize kernels respectively. Skeletonisation displays the thickness as well as the connectivity of the air paths inside the maize kernels. Compared to the raw skeleton (Fig. 6a), the FCCT-roasted skeleton (Fig. 6b) was similar in density and thickness. In contrast, the oven-roasted sample yielded a complex skeleton (Fig. 6c) with a denser porous network of multiple twisting paths and interconnected pores of various thicknesses. The oven-roasted skeleton was also distinctly different from the other skeletons, since a cavity initiation site could be observed as a spider web structure.

\subsection{Quantitative microstructural analysis}

The germ, which remained intact during roasting, was virtually excluded to enable more accurate segmentation of the vitreous and floury endosperm.

\subsubsection{Volume of interest (VOI)}

When manual dissection was used to quantify the volumes of the different endosperm types, the vitreous endosperm was determined to be approximately double the volume of the floury endosperm (Wolf et al., 1952). The mean volumes of interest (VOIs) for the different maize kernels constituents determined using X-ray $\mu \mathrm{CT}$ are presented in Table 1. Oven roasting had a significant $(\mathrm{P} \leq 0.05)$ effect on the air (porosity), more specifically the cavities, and also the floury endosperm. FCCT roasting resulted in no significant $(P>0.05)$ volume changes. In the roasted kernels, air was the component contributing to the largest increase in volume with an increase of $74.3 \%$ and $462.8 \%$ during FCCT and oven roasting respectively. 

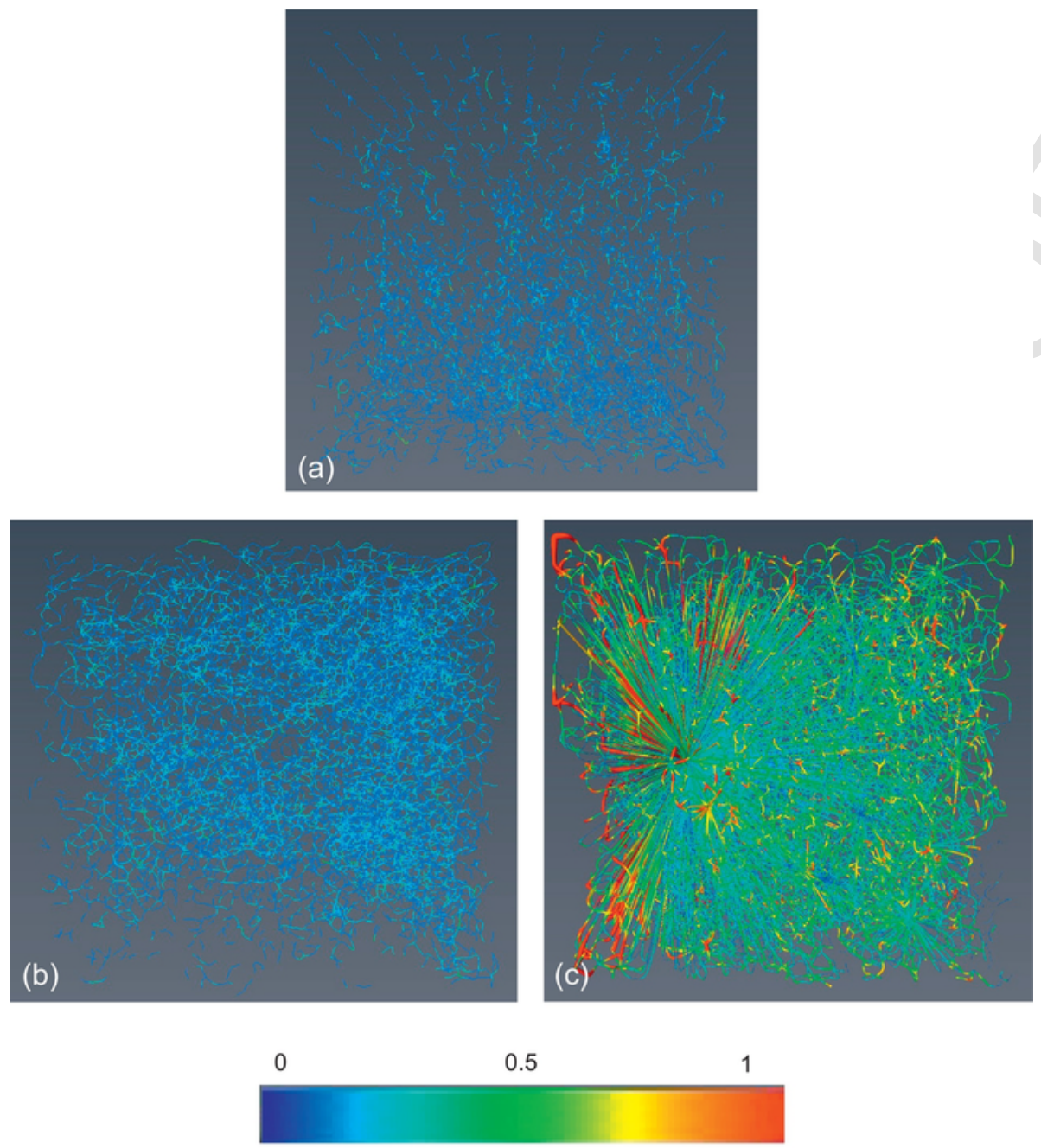

Thickness

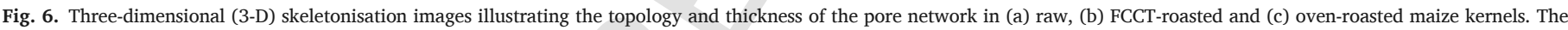

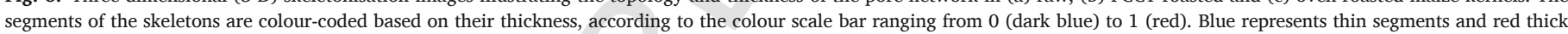
segments, where a thickness of 1 is equal to $10 \mu \mathrm{m}$. (For interpretation of the references to colour in this figure legend, the reader is referred to the web version of this article.)

Table 1

Mean volumes of interest (VOIs), percentage object volumes (POVs), expansion ratios (ERs) and vitreous-to-floury endosperm ratios (V:Fs) of the two roasting methods.

\begin{tabular}{|c|c|c|c|c|c|c|}
\hline & FCCT & & & Oven & & \\
\hline Properties & Raw $(n=10)$ & Roasted $(\mathrm{n}=10)$ & $\%$ increase/decrease & $\operatorname{Raw}(\mathrm{n}=10)$ & Roasted $(\mathrm{n}=10)$ & $\%$ increase/decrease \\
\hline \multicolumn{7}{|l|}{ VOIs $\left(\mathrm{mm}^{3}\right)$} \\
\hline Whole kernel & $336.8 \pm 43.0^{\mathrm{a}}$ & $348.3 \pm 43.5^{\mathrm{a}}$ & 3.4 & $344.7 \pm 27.7^{\mathrm{a}}$ & $381.8 \pm 46.6^{\mathrm{a}}$ & 10.8 \\
\hline Total air & $11.3 \pm 5.7^{\mathrm{b}}$ & $19.7 \pm 8.4^{b}$ & 74.3 & $8.6 \pm 6.7^{b}$ & $48.4 \pm 43.1^{\mathrm{a}}$ & 462.8 \\
\hline Cavities & $9.2 \pm 6.1^{\mathrm{b}}$ & $17.1 \pm 9.2^{\mathrm{b}}$ & 85.9 & $6.9 \pm 6.7^{b}$ & $47.0 \pm 43.2^{\mathrm{a}}$ & 581.2 \\
\hline Pores & $2.1 \pm 1.6^{\mathrm{a}}$ & $2.7 \pm 2.4^{\mathrm{a}}$ & 28.6 & $1.8 \pm 1.0^{\mathrm{a}}$ & $1.4 \pm 0.79^{\mathrm{a}}$ & -22.2 \\
\hline Germ & $46.4 \pm 7.4^{\mathrm{a}}$ & $47.3 \pm 6.9^{\mathrm{a}}$ & 1.9 & $47.0 \pm 6.6^{\mathrm{a}}$ & $49.6 \pm 6.9^{\mathrm{a}}$ & 5.5 \\
\hline Floury endosperm & $71.3 \pm 19.2^{\mathrm{ab}}$ & $78.4 \pm 34.5^{\mathrm{ab}}$ & 10.0 & $59.4 \pm 10.7^{b}$ & $95.3 \pm 53.3^{\mathrm{a}}$ & 60.4 \\
\hline Vitreous endosperm & $219.1 \pm 39.6^{a}$ & $222.6 \pm 37.0^{\mathrm{a}}$ & 1.6 & $238.2 \pm 22.3^{\mathrm{a}}$ & $237.0 \pm 19.2^{\mathrm{a}}$ & -0.5 \\
\hline Total endosperm & $290.4 \pm 36.9^{a}$ & $301.0 \pm 39.7^{\mathrm{a}}$ & 3.7 & $297.6 \pm 21.8^{\mathrm{a}}$ & $332.3 \pm 47.4^{\mathrm{a}}$ & 11.7 \\
\hline \multicolumn{7}{|l|}{ POV (\%) } \\
\hline Material & $96.6 \pm 1.6^{\mathrm{a}}$ & $94.3 \pm 2.0^{\mathrm{a}}$ & -2.3 & $97.5 \pm 2.0^{\mathrm{a}}$ & $87.3 \pm 8.5^{\mathrm{b}}$ & -10.2 \\
\hline Air (porosity) & $3.4 \pm 1.6^{\mathrm{b}}$ & $5.7 \pm 2.0^{\mathrm{b}}$ & 2.3 & $2.5 \pm 2.0^{\mathrm{b}}$ & $12.7 \pm 8.5^{\mathrm{a}}$ & 10.2 \\
\hline Cavities & $2.7 \pm 1.7^{\mathrm{b}}$ & $4.9 \pm 2.3^{b}$ & 2.2 & $2.0 \pm 2.0^{\mathrm{b}}$ & $12.3 \pm 8.5^{\mathrm{a}}$ & 10.3 \\
\hline Pores & $0.63 \pm 0.42^{\mathrm{a}}$ & $0.76 \pm 0.72^{\mathrm{a}}$ & 0.13 & $0.51 \pm 0.25^{\mathrm{a}}$ & $0.37 \pm 0.20^{\mathrm{a}}$ & -0.14 \\
\hline ER & $1.03 \pm 0.07^{\mathrm{a}}$ & & - & $1.11 \pm 0.17^{\mathrm{b}}$ & & - \\
\hline $\mathrm{V}: \mathrm{F}$ & $3.3 \pm 0.98^{\mathrm{ab}}$ & $3.2 \pm 0.98^{\mathrm{b}}$ & -3.0 & $4.2 \pm 0.95^{\mathrm{a}}$ & $3.0 \pm 1.2^{\mathrm{b}}$ & -28.6 \\
\hline
\end{tabular}

Values are means \pm standard deviation of ten replicates $(\mathrm{n}=10)$. Different letters in the same row indicate significant differences $(\mathrm{P} \leq 0.05)$. 
Roasting had a greater effect on the floury (increase of $10.0 \%$ and $60.4 \%$ for FCCT and oven roasting respectively) than vitreous endosperm, due to it being softer and closer to the centre of the maize kernel where internal cracks initiated. The vitreous endosperm volume increased by $1.6 \%$ (FCCT) and decreased by $0.5 \%$ (oven) (Table 1 ). The decrease could be due to the vitreous endosperm becoming softer during roasting and thus the greyscale values decreased and were regarded as softer, floury endosperm. Roasting had no significant $(P>0.05)$ effect on the total endosperm volume.

The germ was not significantly $(\mathrm{P}>0.05)$ affected during roasting, and increases of $1.9 \%$ and $5.5 \%$ were observed for FCCT and oven roasting respectively. The increase in whole kernel volume during FCCT roasting was only $3.4 \%$ in comparison to the $10.8 \%$ increase during oven roasting. This was due to the large increase in air volume related to oven roasting and the formation of a more open crack network. In a previous study, oven roasting also resulted in an almost threefold increase in whole wheat kernel VOI compared to FCCT roasting (Schoeman, Du Plessis et al., 2016). X-ray $\mu \mathrm{CT}$ enables faster and more accurate analysis of total kernel volume as well as the different internal components compared to volume displacement and manual dissection.

\subsubsection{Percentage object volume (POV)}

$\mathrm{POV}$ is an indication of the percentage volume of a specific component in the kernel relative to the entire kernel. Since yield is a highly desirable property for the milling industry, understanding the relative contribution of the material (excluding all cavities and pores) to the total maize kernel is relevant. In the present study, the decrease in material POV was significantly $(\mathrm{P} \leq 0.05)$ higher for oven roasting $(10.2 \%)$ compared to FCCT roasting (2.3\%) (Table 1$)$.

\subsubsection{Porosity (cavities and pores)}

Pores and voids are inherent to maize kernels due to the porous nature of the endosperm (Chang, 1988). Oven-roasted samples had a significantly $(\mathrm{P} \leq 0.05)$ higher porosity $(12.7 \%)$ than FCCT-roasted samples $(5.7 \%)$ (Table 1$)$. Due to the lower porosity, FCCT roasting is expected to deliver a higher-quality kernel in terms of milling yield. Little is known about the development of cavities and pores during roasting. In order to obtain a better understanding of the size distribution of the air inside maize kernels, the total porosity was further subdivided into larger cavities and smaller pores, quantified as percentage cavities and percentage pores. Fig. 4 demonstrates the difference between pores and cavities as depicted in 2-D. A recent study on wheat considered the porosity as the total air in the sample; thus, the entirety of cavities and pores (Schoeman, Du Plessis et al., 2016). Here it was also reported that the porosity of wheat kernels was significantly $(\mathrm{P} \leq 0.05)$ higher after oven roasting.

The percentage cavities for the raw samples were $2.7 \pm 1.7 \%$ (FCCT) and $2.0 \pm 2.0 \%$ (oven) (Table 1). Guelpa, Du Plessis et al. (2015) reported the percentage cavities and percentage pores $(n=16)$ of raw whole maize kernels as $1.8 \%$ and $0.012 \%$ respectively. The percentage cavities in the oven-roasted $(12.3 \pm 8.5 \%)$ samples was significantly $(\mathrm{P} \leq 0.05)$ higher than in the FCCT-roasted $(4.9 \pm 2.3 \%)$ samples. In expanded cereal products, more cavities are formed due to less structural integrity. During oven roasting, large cavities are created by coalescence of adjacent cells when the cell walls rupture.

The percentage pores were not significantly $(P>0.05)$ affected during roasting. The percentage pores of the oven-roasted samples decreased by $0.14 \%$, while it increased by $0.13 \%$ for the FCCT-roasted samples (Table 1). It is likely that during FCCT roasting, some new pores developed, whereas during oven roasting, the existing pores fused to form larger cavities. Rapid evaporation of moisture inside the maize kernels results in the formation of new pores. Due to moisture loss, these pores grow and fuse, especially during oven roasting, with neighbouring pores creating larger cavities (Sumithra \& Bhattacharya, 2008). In the present study, the minimum detectable pore size was $41 \mu \mathrm{m}$ in diameter detectable in a FCCT-roasted sample. Pores in popped popcorn are usually 30 to $60 \mu \mathrm{m}$ in diameter, whereas pore diameters of maize puffed using puffing guns are usually in the 50- to $200-\mu \mathrm{m}$ range (Schwartzberg, Wu, Nussinovitch, \& Mugerwa, 1995).

Harder maize kernels, having fewer cavities and pores, will have a better dry milling quality and yield compared to softer kernels (Guelpa, Du Plessis et al., 2015). During wet milling, kernels with a high cavity percentage will steep more rapidly and lose part of their starch in the steep water (Gunasekaran, Deshpande, Paulsen, \& Shove, 1985). Furthermore, the protein is case-hardened in highly porous kernels, which may lead to difficulty in separating the protein and starch, resulting in less recoverable starch.

Using gas pycnometry, it was shown that adjacent cells that are closed and not interconnected might be counted as interconnected regions if there is a small crack in the cell wall that could allow gas to penetrate. X-ray $\mu \mathrm{CT}$ is thus more accurate as it can distinguish between adjacent closed cells and interconnected regions (Trater, Alavi, \& Rizvi, 2005).

\subsubsection{Expansion ratio (ER)}

A large ER is associated with greater air volumes and a higher density decrease (Sumithra \& Bhattacharya, 2008). Oven roasting produced kernels with a significantly $(P \leq 0.05)$ higher sectional expansion $(1.11 \pm 0.17)$ than FCCT roasting $(1.03 \pm 0.07)$, indicating a much larger difference in the volumes of the oven-roasted kernels before and after roasting (Table 1). Visual assessment also indicated a bulged effect, especially toward the middle region, indicating localised high expansion, in the oven-roasted kernels. This is attributed to the fracturing of the cell walls that separate pores leading to an increase in cavity volume. In a study by Mrad et al. (2014), on the textural properties of roasted purple maize, the ER was in the range of 1.44 to 3.13 . The most acceptable ER was found to be approximately 1.5, as kernels at this level were expanded without being deformed. This will however depend on the roasting method used and prevailing conditions. There are a large number of parameters that affect the degree of expansion in cereals, which are connected to both the compositional characteristics of the raw material (Jones, Chinnaswamy, Tan, \& Hanna, 2000) and the processing conditions (Mariotti, Alamprese, Pagani, \& Lucisano, 2006).

The internal pressure created inside the kernel causes expansion. Even though the roasting process is conducted at a low moisture content, the use of high temperature for a short time suddenly releases steam, leaving behind an expanded structure (Sumithra \& Bhattacharya, 2008). Greater air volumes (oven-roasted samples) are synonymous with greater expansion ratios. The expansion of a sample is primarily reliant on the development of air pockets, which are formed when vapour expands. A relationship exists between porosity and the expanded volume since the entrapped air plays an important role in expansion (Boischot, Moraru, \& Kokini, 2003).

The mechanism that governs cereal expansion is similar for all thermal processes (Boischot et al., 2003). During heating, the starch matrix undergoes a phase transition in the presence of water from a glassy to a rubbery state, which allows expansion and formation of the final structure (Boischot et al., 2003). Furthermore, moisture content plays a critical role in cereal expansion due to the ability of water vapour to generate the driving force during the roasting process and its effect on the extensional viscosity and phase transitions of the food matrix. Oven roasting had a significant $(\mathrm{P} \leq 0.05)$ effect on kernel weight and resulted in a loss of $2.64 \%$, while the weight remained almost unaffected during FCCT roasting (Table 2). Oven roasting relies on only air movement while the sample is stationary, imparting a higher internal pressure and resulting in more moisture loss. 
Table 2

Mean relative densities of the different maize kernel constituents and the weight of the raw, FCCT- and oven-roasted kernels.

\begin{tabular}{|c|c|c|c|c|c|c|}
\hline \multirow[t]{2}{*}{ Properties } & \multicolumn{3}{|l|}{ FCCT } & \multicolumn{3}{|l|}{ Oven } \\
\hline & Raw $(n=10)$ & Roasted $(\mathrm{n}=10)$ & $\%$ decrease & Raw $(n=10)$ & Roasted $(n=10)$ & $\%$ decrease \\
\hline \multicolumn{7}{|c|}{ Relative density $\left(\mathrm{g} / \mathrm{cm}^{3}\right)$} \\
\hline Whole kernel & $1.56 \pm 0.30^{\mathrm{a}}$ & $1.53 \pm 0.20^{\mathrm{a}}$ & 1.9 & $1.58 \pm 0.60^{\mathrm{a}}$ & $1.48 \pm 0.80^{\mathrm{b}}$ & 6.3 \\
\hline Material & $1.58 \pm 0.30^{\mathrm{a}}$ & $1.57 \pm 0.30^{\mathrm{ab}}$ & 0.63 & $1.61 \pm 0.50^{\mathrm{a}}$ & $1.53 \pm 0.60^{b}$ & 5.0 \\
\hline Germ & $1.58 \pm 0.50^{\mathrm{a}}$ & $1.56 \pm 0.50^{\mathrm{a}}$ & 1.3 & $1.60 \pm 0.60^{\mathrm{a}}$ & $1.55 \pm 0.90^{\mathrm{a}}$ & 3.1 \\
\hline Floury endosperm & $1.44 \pm 0.40^{\mathrm{a}}$ & $1.35 \pm 0.60^{\mathrm{a}}$ & 6.3 & $1.45 \pm 0.50^{\mathrm{a}}$ & $1.38 \pm 0.90^{\mathrm{a}}$ & 4.8 \\
\hline Vitreous endosperm & $1.60 \pm 0.50^{\mathrm{a}}$ & $1.58 \pm 0.40^{\mathrm{a}}$ & 1.3 & $1.62 \pm 0.60^{\mathrm{a}}$ & $1.58 \pm 0.80^{\mathrm{a}}$ & 2.5 \\
\hline Weight (mg) & $424.1 \pm 54.08^{\mathrm{ab}}$ & $420.78 \pm 55.51^{\mathrm{ab}}$ & 0.78 & $449.32 \pm 33.73^{\mathrm{a}}$ & $437.48 \pm 35.26^{\mathrm{b}}$ & 2.64 \\
\hline
\end{tabular}

Values are means \pm standard deviation of ten replicates $(n=10)$. Different letters in the same row indicate significant differences $(P \leq 0.05)$.

A previous study comparing roasted peanuts using superheated steam and conventional oven roasting (without steam) demonstrated that, during oven roasting, the rate of decrease in moisture content was much higher compared to the superheated steam method (Idrus \& Yang, 2012). This study also suggested that, as a novel method for food processing, superheated steam roasting is more convenient and at the same time and temperature conditions, favourable characteristics, i.e. colour, texture and microstructure, are maintained.

\subsubsection{Endosperm ratios}

Guelpa, Du Plessis, and Manley (2016) reported a V:F of 0.69 to 7.18 for good milling hybrids and a range of 0.20 to 3.17 for poor milling hybrids. The authors also indicated V:F to be a good descriptor of maize milling quality. According to Table 1 , the V:F decreased from $3.3 \pm 0.98$ to $3.2 \pm 0.98$ for FCCT-roasted samples and from $4.2 \pm 0.95$ to $3.0 \pm 1.2$ for oven-roasted samples. The significant $(\mathrm{P} \leq 0.05)$ decrease of the $\mathrm{V}$ : $\mathrm{F}$ for the oven-roasted samples was due to the large increase in floury endosperm and the decrease in vitreous endosperm VOI.

Previously, a dissecting microscope and electronic planimeter were used to quantify the $\mathrm{F}: \mathrm{V}$ (range of 0.12 to 0.30 ) in popped maize kernels (Pordesimo, Anantheswaran, \& Mattern, 1991). Expansion was generally higher when the $\mathrm{F}: \mathrm{V}$ was lower. In contrast, in the present study study, kernels with a higher ER (oven-roasted) had the lowest $\mathrm{V}: \mathrm{F}$ (or highest F:V). It can be hypothesised that, because the floury endosperm had a less dense structure, the vapour that was generated internally, diffused into the voids leading to an increase in internal pressure (Pordesimo et al., 1991). This caused the floury endosperm volume to increase more, and this region thus underwent more structural alteration in comparison to the vitreous endosperm. Therefore, a lower V:F was indicative of an increase in floury endosperm volume.

Blandino et al. (2010) determined the V:F (range of 0.2 to 4.8 ) of maize kernels using manual dissection in combination with an image analysis system. These methods are destructive and time-consuming, and thus not practical for large sample sizes. X-ray $\mu \mathrm{CT}$ enabled more accurate and non-destructive segmentation of the vitreous and floury endosperm into specific ROIs in order to quantify the volumes and determine the V:F. X-ray $\mu \mathrm{CT}$ is unfortunately time-consuming with cost implications when analysing a large number of samples. However, a recent study demonstrated a high-throughput approach where 150 maize kernels were scanned simultaneously (Guelpa et al., 2016). Although this resulted in reduced resolution scans, sufficient segmentation and quantification of ROIs were still possible.

\subsubsection{Relative density analysis}

Density is an important property, which depends on the internal structure of food (Kelkar, Boushey, \& Okos, 2015). For porous foods, accurate density measurements are challenging because conventional methods are tedious, operator-dependent and incapable of precise volume measurements. Kelkar et al. (2015) overcame such limitations by developing a methodology, using both X-ray digital radiography and computed tomography (CT) to determine the apparent density of foods directly. X-ray CT was more efficient giving results comparable with conventional methods.

$\mathrm{X}$-ray $\mu \mathrm{CT}$ enables images to be generated that map variances in $\mathrm{X}$-ray attenuation within a sample, and this relates closely to density (Schoeman, Williams et al., 2016). Each voxel in an image has a specific grey value, which is reliant on density. The higher the grey values, the higher the attenuation coefficients and the higher the material density. Fig. 7 represents a 3-D volume illustrating relative density differences in a maize kernel.

The mean relative densities of all the constituents decreased during roasting (Table 2). In contrast to wheat, here again it was important to evaluate both endosperm types, since a greater decrease in vitreous endosperm will have a significant effect on milling yield. It should be noted that the relative densities of the individual tissues, e.g. floury endosperm, include the air in that region. Oven roasting resulted in a significant $(\mathrm{P} \leq 0.05)$ decrease in whole kernel and material relative density, while no significant $(\mathrm{P}>0.05$ ) density decreases were observed for FCCT roasting. During oven roasting, a 6.3\% decrease in whole kernel relative density was obtained in comparison to a $1.9 \%$ decrease during FCCT roasting. This can be attributed to the large increase in air volume that is accounted for in the whole kernel density of the oven-roasted kernels. These results are in accordance with a previous study, which found a significant decrease in density due to an increase in the air volume after roasting coffee beans (Dutra, Oliveira, Franca, Ferraz, \& Afonso, 2001).

Voids in roasted kernels make up a large volume of the kernel, suggesting that whole kernel density may not be as informative of kernel

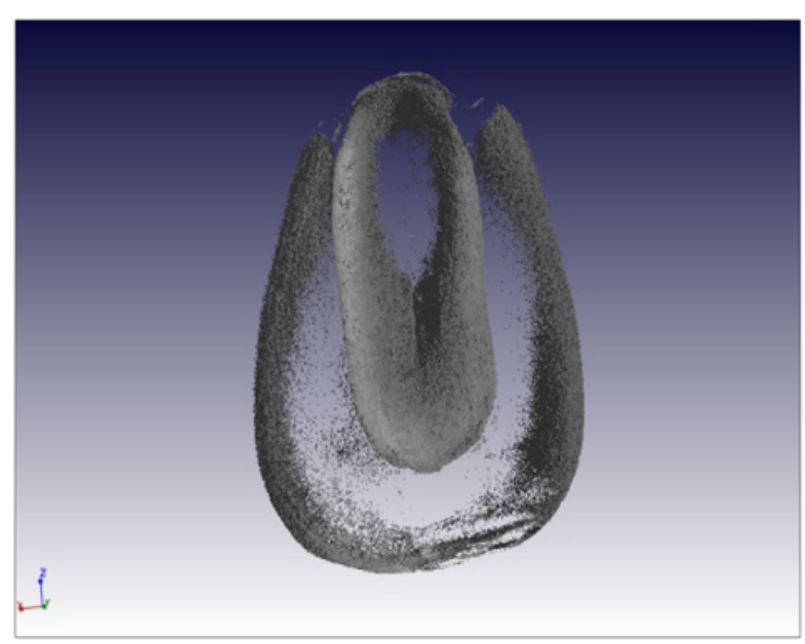

Fig. 7. A semi-transparent 3-D volume illustrating the density differences of the maize constituents, where the less dense area (floury endosperm) is shown with partial transparency and the more dense regions (germ and vitreous endosperm) in grey. 
hardness as material density (Gustin et al., 2013). Material density (also known as 'true density'), which excludes all air voids, remained almost unaffected (decrease of $0.63 \%$ ) during FCCT roasting, but decreased significantly ( $\mathrm{P} \leq 0.05$ ) by $5.0 \%$ during oven roasting. Similarly, Schoeman, Du Plessis et al. (2016) reported FCCT roasting to have no effect on the material density of wheat.

Larger relative density decreases took place during oven roasting for the germ (3.1\%) and vitreous endosperm (2.5\%), in comparison to FCCT roasting (germ $=1.3 \%$; vitreous endosperm $=1.3 \%$ ). The floury endosperm was the component contributing most to the relative density decrease, resulting in a $6.3 \%$ and $4.8 \%$ decrease in the FCCT- and oven-roasted kernels respectively. The absence of a thick protein matrix, which covers the starch granules in the floury endosperm, led to the formation of cracks, which ultimately developed into larger cavities when moisture loss was experienced during roasting. Fewer intracellular air spaces were found in the tightly packed vitreous endosperm as opposed to the loosely packed floury endosperm, explaining the higher density.

Gustin et al. (2013) correlated maize kernel density with kernel volume and internal air space. Similarly, in the current study the whole kernel density was affected by the increased porosity during roasting. The relative density results corresponded well with the results obtained by Guelpa, Du Plessis et al. (2015), who made use of an X-ray $\mu$ CT density calibration for raw maize kernels $(\mathrm{n}=16)$ where the density ranges were 1.28 to $1.62 \mathrm{~g} / \mathrm{cm}^{3}, 1.60$ to $1.75 \mathrm{~g} / \mathrm{cm}^{3}$ and 1.21 to $1.53 \mathrm{~g} / \mathrm{cm}^{3}$ for material, vitreous endosperm and floury endosperm respectively.

Jha (2005) found that the density of grains decreased during roasting due to expansion, development of pores and, consequently, moisture loss. Chung et al. (2011) also reported a decrease in maize density due to puffing. A previous study on maize roasting (using a gas-operated roaster) reported a density decrease of $41.9 \%$ at $137{ }^{\circ} \mathrm{C}$ (Felsman, Harvey, Linnerud, \& Smith, 1976). This decrease was much higher in comparison with the results presented in Table 2. Oven and FCCT roasting (both using electric heat) utilised in the present study made use of a higher roasting temperature and shorter roasting time. This indicates that differences in the roasting methods and conditions may account for this discrepancy.

Conventional density measurements, i.e. floating tests (Blandino et al., 2010), might lead to misleading results as internal cavities will greatly influence the results (Guelpa, Du Plessis et al., 2015). Conventional density methods overlook the influence of pores and cavities, while with X-ray $\mu \mathrm{CT}$, it is possible to determine only the material density. X-ray $\mu \mathrm{CT}$ is capable of disregarding cavities that could have a negative influence on the results (Gustin et al., 2013). The ability of $\mu \mathrm{CT}$ to divide the maize kernel into biological material and air, for volume and density measurements, provides higher resolution information about kernel characteristics than either pycnometry or floating tests.

\subsection{Dry milling properties}

No significant $(\mathrm{P}>0.05)$ differences were observed between the HLM of the raw $\left(78.47 \mathrm{~kg} \mathrm{hL}^{-1}\right)$, FCCT- $\left(78.40 \mathrm{~kg} \mathrm{hL}^{-1}\right)$ and oven-roasted $\left(78.23 \mathrm{~kg} \mathrm{hL}^{-1}\right)$ samples. The values were similar to the average HLM of $78.30 \mathrm{~kg} \mathrm{hL}^{-1}$ reported for the 2014/2015 maize season (The South African Grain Laboratory [SAGL], 2016). Milling yield of the control $(77.06 \pm 0.49 \%)$, FCCT- $(76.05 \pm 1.37 \%)$ and oven-roasted $(75.79 \pm 0.56 \%)$ samples was not significantly $(P>0.05)$ different (Table 3). Oven-roasted samples had the lowest milling yield, and this might be attributed to the higher porosity (Table 1 ) and lower density (Table 2). The porosity level caused reductions in mechanical strength, yielding softer, finer flour compared to FCCT roasting. These results are in agreement with the average extraction of $78.7 \%$ reported for white
Table 3

Dry milling properties of the raw and roasted maize samples.

\begin{tabular}{llll}
\hline Sample & $\begin{array}{l}\text { HLM } \\
\left(\mathrm{kg} \mathrm{hL}^{-1}\right)^{\mathrm{b}}\end{array}$ & $\begin{array}{l}\text { Milling yield } \\
(\%)^{\mathrm{b}}\end{array}$ & $\begin{array}{l}\text { Hominy chop } \\
(\%)^{\mathrm{c}}\end{array}$ \\
\hline Raw & $78.47 \pm 0.29^{\mathrm{a}}$ & $77.06 \pm 0.49^{\mathrm{a}}$ & $22.97 \pm 0.50^{\mathrm{a}}$ \\
FCCT & $78.40 \pm 0.44^{\mathrm{a}}$ & $76.05 \pm 1.37^{\mathrm{a}}$ & $23.97 \pm 1.34^{\mathrm{a}}$ \\
Oven & $78.23 \pm 0.55^{\mathrm{a}}$ & $75.79 \pm 0.56^{\mathrm{a}}$ & $24.20 \pm 0.53^{\mathrm{a}}$ \\
\hline
\end{tabular}

Values are presented as mean \pm standard deviation of three replicates $(n=3)$. Mean values with different superscripts in a column differ significantly $(\mathrm{P} \leq 0.05)$.

b Mean values of single measurements from three replicates.

c Mean values of duplicate measurements from three replicates.

maize during the 2014/2015 season (SAGL, 2016). The hominy chop was also not significantly ( $P>0.05$ ) influenced (Table 3 ). The raw, FCCT- and oven-roasted samples had a hominy chop of $22.94 \pm 0.49 \%$, $23.95 \pm 1.37 \%$ and $24.21 \pm 0.56 \%$ respectively, and all the samples could be classified within the good intermediate range.

\section{Conclusion}

Raw, sound maize kernels have a compact and homogenous internal microstructure. Roasting caused an increase in kernel volume and a decrease in relative density, with the changes being more profound during oven roasting in comparison to FCCT roasting. In the present study, roasting increased the porosity of maize kernels comprising cavities and pores of different sizes. Kernel density and porosity were shown to be inversely correlated, with the oven-roasted samples having the highest density decrease and highest porosity increase. FCCT roasting had almost no effect on the material density of the samples, in contrast to oven roasting. Although structural changes occurred during roasting, the milling properties were not significantly $(P>0.05)$ influenced, indicating that roasting did not comprise milling yield and quality. Maize with good milling properties contains a high proportion of vitreous endosperm and will thus result in great yields with high economic value. Further investigations are needed to assess the functional characteristics of roasted maize.

Although the present study was motivated by an innovative roasting method, FCCT roasting, the results also contributed to an improved understanding of the effect of high-temperature processing on the internal microstructure of cereal grains in general. Taking all the measurements into account, the FCCT roaster, with the rotating cylinder, was a more effective roasting method compared to oven roasting. The qualitative results also illustrated the less invasive effect of FCCT roasting on the kernel microstructure. FCCT roasting could thus be a more suitable roasting method for food applications. Even though X-ray $\mu \mathrm{CT}$ is ideal as a non-invasive tool for microstructural analysis, it is currently mainly used as a research tool, and the application thereof for in-line measurements still needs further development. In the food industry, 2-D X-ray images could be used for rapid and real-time quality control analyses.

\section{Acknowledgements}

Financial assistance was provided by the National Research Foundation (NRF) (grant-specific unique reference number (UID) 76641 and 88057; NRF Scarce Skills Doctoral scholarship) and the Winter Cereal Trust (study grant for Letitia Schoeman). Stephan le Roux (CAF, CT-Scanner Unit) is acknowledged for his X-ray $\mu$ CT assistance.

\section{References}

Bellido, G.G., Scanlon, M.G., Page, J.H., Hallgrimsson, B., 2006. The bubble size distribution in wheat flour dough. Food Research International 39 (10), 1058-1066. 
Blandino, M., Mancini, M.C., Peila, A., Rolle, L., Vanara, F., Reyneri, A., 2010. Determination of maize kernel hardness: Comparison of different laboratory tests to predict dry-milling performance. Journal of the Science of Food and Agriculture 90 (11), 1870-1878.

Boischot, C., Moraru, C., Kokini, J., 2003. Factors that influence the microwave expansion of glassy amylopectin extrudates. Cereal Chemistry 80 (1), 56-61.

Cantre, D., East, A., Verboven, P., Trejo Araya, X., Herremans, E., Nicolaï, B.M., et al., 2014. Microstructural characterisation of commercial kiwifruit cultivars using X-ray micro computed tomography. Postharvest Biology and Technology 92, 79-86.

Cantre, D., Herremans, E., Verboven, P., Ampofo-Asiama, J., Nicolaï, B., 2014. Characterization of the 3-D microstructure of mango (Mangifera indica L. cv. Carabao) during ripening using X-ray computed microtomography. Innovative Food Science \& Emerging Technologies 24, 28-39.

Carrera, Y., Utrilla-Coello, R., Bello-Pérez, A., Alvarez-Ramirez, J., Vernon-Carter, E.J., 2015. In vitro digestibility, crystallinity, rheological, thermal, particle size and morphological characteristics of pinole, a traditional energy food obtained from toasted ground maize. Carbohydrate Polymers 123, 246-255.

Chang, C., 1988. Measuring density and porosity of grain kernels using a gas pycnometer. Cereal Chemistry 65 (1), 13-15.

Chung, H.S., Chung, S.K., Youn, K.S., 2011. Effects of roasting temperature and time on bulk density, soluble solids, browning index and phenolic compounds of corn kernels. Journal of Food Processing and Preservation 35 (6), 832-839.

Delcour, J., Hoseney, R.C., 2010. Principles of cereal science and technology, 3rd ed. AACC International, St. Paul, MN.

Dutra, E., Oliveira, L., Franca, A., Ferraz, V., Afonso, R., 2001. A preliminary study on the feasibility of using the composition of coffee roasting exhaust gas for the determination of the degree of roast. Journal of Food Engineering 47 (3), 241-246.

Felsman, R., Harvey, R., Linnerud, A., Smith, F., 1976. Effect of roasting temperature on corn grain characteristics. Journal of Animal Science 42 (2), 476-480.

Food and Agriculture Organization of the United Nations, 2015. FAOSTAT: Crops. Retrieved from http://faostat3.fao.org/download/Q/QC/E

Frisullo, P., Barnabà, M., Navarini, L., Del Nobile, M., 2012. Coffea arabica beans microstructural changes induced by roasting: An X-ray microtomographic investigation. Journal of Food Engineering 108 (1), 232-237.

Frisullo, P., Marino, R., Laverse, J., Albenzio, M., Del Nobile, M., 2010. Assessment of intramuscular fat level and distribution in beef muscles using X-ray microcomputed tomography. Meat Science 85 (2), 250-255.

Gonzales-Barron, U., Butler, F., 2008. Discrimination of crumb grain visual appearance of organic and non-organic bread loaves by image texture analysis. Journal of Food Engineering 84 (3), 480-488.

Guelpa, A., Bevilacqua, M., Marini, F., O'Kennedy, K., Geladi, P., Manley, M., 2015. Application of Rapid Visco Analyser (RVA) viscograms and chemometrics for maize hardness characterisation. Food Chemistry 173, 1220-1227.

Guelpa, A., Du Plessis, A., Kidd, M., Manley, M., 2015. Non-destructive estimation of maize (Zea mays L.) kernel hardness by means of an X-ray micro-computed tomography $(\mu \mathrm{CT})$ density calibration. Food and Bioprocess Technology 8, 1419-1429.

Guelpa, A., Du Plessis, A., Manley, M., 2016. A high-throughput X-ray micro-computed tomography $(\mu \mathrm{CT})$ approach for measuring single kernel maize (Zea mays L.) volumes and densities. Journal of Cereal Science 69, 321-328.

Gujral, H.S., Sharma, P., Sharma, R., 2013. Antioxidant properties of sand roasted and steam cooked Bengal gram (Cicer arietinum). Food Science and Biotechnology 22 (1), 183-188.

Gunasekaran, S., Deshpande, S., Paulsen, M., Shove, G., 1985. Size characterization of stress cracks in corn kernels. Transactions of ASAE 28 (5), 1668-1672.

Gunasekaran, S., Paulsen, M.R., 1986. Automatic, nondestructive detection of corn kernel defects. In: International advances in nondestructive testing. 12, pp. 95-115.

Gustin, J.L., Jackson, S., Williams, C., Patel, A., Armstrong, P., Peter, G.F., Settles, A.M., 2013. Analysis of maize (Zea mays) kernel density and volume using microcomputed tomography and single-kernel near-infrared spectroscopy. Journal of Agricultural and Food Chemistry 61 (46), 10872-10880.

Haedelt, J., Beckett, S., Niranjan, K., 2007. Bubble-included chocolate: Relating structure with sensory response. Journal of Food Science 72 (3), 138-142.

Herremans, E., Melado-Herreros, A., Defraeye, T., Verlinden, B., Hertog, M., Verboven, P., ... Estrade, P., 2014. Comparison of X-ray CT and MRI of watercore disorder of different apple cultivars. Postharvest Biology and Technology 87, 42-50.

Herremans, E., Verboven, P., Bongaers, E., Estrade, P., Verlinden, B.E., Wevers, M., et al., 2013. Characterisation of 'Braeburn' browning disorder by means of X-ray micro-CT. Postharvest Biology and Technology 75, 114-124.

Herremans, E., Verboven, P., Verlinden, B.E., Cantre, D., Abera, M., Wevers, M., Nicolaï, B.M., 2015. Automatic analysis of the 3-D microstructure of fruit parenchyma tissue using X-ray micro-CT explains differences in aeration. BMC Pant Biology 15 (1), 1-14.

Idrus, N.F.M., Yang, T.A., 2012. Comparison between roasting by superheated steam and by convection on changes in colour, texture and microstructure of peanut (Arachis hypogaea). Food Science and Technology Research 18 (4), 515-524.

Jha, S., 2005. Mathematical simulation of roasting of grain. Journal of Food Engineering 71 (3), 304-310.

Jones, D., Chinnaswamy, R., Tan, Y., Hanna, M., 2000. Physiochemical properties of ready-to-eat breakfast cereals. Cereal Foods World 45 (4), 164-168.

Kabak, B., 2009. The fate of mycotoxins during thermal food processing. Journal of the Science of Food and Agriculture 89 (4), 549-554.

Kelkar, S., Boushey, C.J., Okos, M., 2015. A method to determine the density of foods using X-ray imaging. Journal of Food Engineering 159, 36-41.

Khan, N., Zaman, R., Elahi, M., 1991. Effect of heat treatments on the phytic acid content of maize products. Journal of the Science of Food and Agriculture 54 (1), 153-156.

Krings, U., Berger, R., 2001. Antioxidant activity of some roasted foods. Food Chemistry $72(2), 223-229$.
Lammertyn, J., Dresselaers, T., Van Hecke, P., Jancsók, P., Wevers, M., Nicolaï, B., 2003. MRI and X-ray CT study of spatial distribution of core breakdown in 'conference' pears. Magnetic Resonance Imaging 21 (7), 805-815.

Lassoued, N., Babin, P., Della Valle, G., Devaux, M.-F., Réguerre, A.-L., 2007. Granulometry of bread crumb grain: Contributions of 2D and 3D image analysis at different scale. Food Research International 40 (8), 1087-1097.

Lim, K.S., Barigou, M., 2004. X-ray micro-computed tomography of cellular food products Food Research International 37 (10), 1001-1012.

Maire, E., Withers, P.J., 2014. Quantitative X-ray tomography. International Materials Reviews 59 (1), 1-43.

Mariotti, M., Alamprese, C., Pagani, M.A., Lucisano, M., 2006. Effect of puffing on ultrastructure and physical characteristics of cereal grains and flours. Journal of Cereal Science 43 (1), 47-56.

Mendoza, F., Verboven, P., Mebatsion, H.K., Kerckhofs, G., Wevers, M., Nicolaï, B., 2007 Three-dimensional pore space quantification of apple tissue using X-ray computed microtomography. Planta 226 (3), 559-570.

Moreira, R.G., 2001. Impingement drying of foods using hot air and superheated steam. Journal of Food Engineering 49 (4), 291-295.

Mrad, R., Debs, E., Saliba, R., Maroun, R.G., Louka, N., 2014. Multiple optimization of chemical and textural properties of roasted expanded purple maize using response surface methodology. Journal of Cereal Science 60 (2), 397-405.

Murthy, K.V., Ravi, R., Bhat, K.K., Raghavarao, K.S.M.S., 2008. Studies on roasting of wheat using fluidized bed roaster. Journal of Food Engineering 89 (3), 336-342.

Oboh, G., Ademiluyi, A.O., Akindahunsi, A.A., 2010. The effect of roasting on the nutri tional and antioxidant properties of yellow and white maize varieties. International Journal of Food Science and Technology 45 (6), 1236-1242.

Odjo, S., Malumba, P., Dossou, J., Janas, S., Béra, F., 2012. Influence of drying and hydrothermal treatment of corn on the denaturation of salt-soluble proteins and color parameters. Journal of Food Engineering 109 (3), 561-570.

Pardeshi, I., Chattopadhyay, P., 2014. Whirling bed hot air puffing kinetics of rice-soy ready-to-eat (RTE) snacks. Journal of Ready to Eat Foods 1 (1), 1-10.

Pittia, P., Sacchetti, G., Mancini, L., Voltolini, M., Sodini, N., Tromba, G., Zanini, F., 2011 Evaluation of microstructural properties of coffee beans by synchrotron X-ray microtomography: A methodological approach. Journal of Food Science 76 (2), 222-231.

Pordesimo, L.O., Anantheswaran, R.C., Mattern, P.J., 1991. Quantification of horny and floury endosperm in popcorn and their effects on popping performance in a microwave oven. Journal of Cereal Science 14 (2), 189-198.

Raigar, R.K., Prabhakar, P.K., Srivastav, P.P., 2017. Effect of different thermal treatments on grinding characteristics, granular morphology and yield of ready-to-ea wheat grits. Journal of Food Process Engineering 40 (2)http://dx.doi.org/10.1111/ jfpe. 12363

Ranganathan, V., Nunjundiah, I.T., Bhattacharya, S., 2014. Effect of roasting on rheological and functional properties of sorghum flour. Food Science and Technology International 20 (8), 579-589.

Schoeman, L., Du Plessis, A., Manley, M., 2016. Non-destructive characterisation and quantification of the effect of conventional oven and forced convection continuous tumble (FCCT) roasting on the three-dimensional microstructure of whole wheat kernels using X-ray micro-computed tomography $(\mu \mathrm{CT})$. Journal of Food Engineering 187, 1-13.

Schoeman, L., Williams, P., Du Plessis, A., Manley, M., 2016. X-ray micro-computed tomography $(\mu \mathrm{CT})$ for non-destructive characterisation of food microstructure. Trends in Food Science \& Technology 47, 10-24.

Schwartzberg, H.G., Wu, J.P.C., Nussinovitch, A., Mugerwa, J., 1995. Modelling deformation and flow during vapor-induced puffing. Journal of Food Engineering 25 (3) 329-372.

Shoughy, M.I., Marey, S.A., Abbas, A., 2009. Effect of drying temperatures on stress cracks and breakage susceptibility of corn grains. Process Engineering 26 (1), 453-468.

Song, H.P., Litchfield, J.B., 1994. Measurement of stress cracking in maize kernels by magnetic resonance imaging. Journal of Agricultural Engineering Research 57 (2), $109-118$.

Sumithra, B., Bhattacharya, S., 2008. Toasting of corn flakes: Product characteristics as a function of processing conditions. Journal of Food Engineering 88 (3), 419-428.

Suresh, A., Neethirajan, S., 2015. Real-time 3D visualization and quantitative analysis of internal structure of wheat kernels. Journal of Cereal Science 63, 81-87.

The South African Grain Laboratory, 2016. Maize report 2014-2015. Retrieved from http: //www.sagl.co.za/Maize/Maizereports/20142015season.aspx

Trater, A.M., Alavi, S., Rizvi, S.S.H., 2005. Use of non-invasive X-ray microtomography for characterizing microstructure of extruded biopolymer foams. Food Research International 38 (6), 709-719.

Van Dalen, G., Nootenboom, P., Van Vliet, L.J., 2007. 3D imaging, analysis and modelling of porous cereal products using X-ray microtomography. Image Analysis and Stereology $26,169-177$.

Verboven, P., Kerckhofs, G., Mebatsion, H.K., Ho, Q.T., Temst, K., Wevers, M., et al., 2008 Three-dimensional gas exchange pathways in pome fruit characterized by synchrotron X-ray computed tomography. Plant Physiology 147 (2), 518-527.

Witek, M., Weglarz, W.P., De Jong, L., Van Dalen, G., Blonk, J.C.G., Heussen, P., et al, 2010. The structural and hydration properties of heat-treated rice studied at multiple length scales. Food Chemistry 120 (4), 1031-1040.

Withers, P.J., 2007. X-ray nanotomography. Materials Today 10 (12), 26-34.

Wolf, M., Buzan, C., MacMasters, M.M., Rist, C., 1952. Structure of the mature corn kernel. 1. Gross anatomy and structural relationships. Cereal Chemistry 29 (5), 321-333.

Zhu, L.-J., Dogan, H., Gajula, H., Gu, M.-H., Liu, Q.-Q., Shi, Y.-C., 2012. Study of kernel structure of high-amylose and wild-type rice by X-ray microtomography and SEM. Journal of Cereal Science 55 (1), 1-5.

Zhu, L.-J., Shukri, R., De Mesa-Stonestreet, N.J., Alavi, S., Dogan, H., Shi, Y.-C., 2010. Mechanical and microstructural properties of soy protein-high amylose corn starch 
extrudates in relation to physiochemical changes of starch during extrusion. Journal of Food Engineering 100 (2), 232-238. 